\title{
From Wastes To Functions: Preparation of Layered Double Hydroxides From Industrial Waste And Its Removal Performance Towards Phosphates
}

\section{Liping Xiao}

Qingdao University of Technology

\section{Yan Li}

Liaoning Technical University

Qiaoping Kong ( $\nabla$ kongqiaoping@qut.edu.cn )

Qingdao University of Technology

Yunlong Lan

Qingdao University of Technology

\section{Research Article}

Keywords: Layered double hydroxides, Industrial waste residue, Phosphate, Adsorption, Wastewater

Posted Date: July 12th, 2021

DOI: https://doi.org/10.21203/rs.3.rs-633550/v1

License: (9) This work is licensed under a Creative Commons Attribution 4.0 International License. Read Full License

Version of Record: A version of this preprint was published at Environmental Science and Pollution Research on September 23rd, 2021. See the published version at https://doi.org/10.1007/s11356-02116563-x. 


\section{From wastes to functions: Preparation of layered double hydroxides from} industrial waste and its removal performance towards phosphates

Liping Xiao ${ }^{\mathrm{a}, ~ *}$, Yan $\mathrm{Li}^{\mathrm{b}}$, Qiaoping Kong ${ }^{\mathrm{a}}$, , Yunlong Lan ${ }^{\mathrm{a}}$

${ }^{a}$ School of Environmental and Municipal Engineering, Qingdao University of Technology, Qingdao 266033, PR China

b School of Civil Engineering, Liaoning Technical University, Fuxin 123000, PR China

\section{Abstract}

To control eutrophication and recover phosphate from wastewater, a calcium carbide slag and red mud composite material (CR-LDH) was prepared using industrial waste as raw material for phosphorus adsorption. The morphology and structure of synthesized CR-LDH was characterized by FT-IR, SEM, EDS and XRD measurements. The experimental data can be well described by pseudo-second-order kinetics and Langmuir isotherm models, suggesting that the adsorption process of CR-LDH with respect to phosphate is a chemical and monolayer process. The theoretical maximum adsorption capacity obtained by Langmuir isotherm model is $16.06 \mathrm{mg} \cdot \mathrm{g}^{-1}$ at $25{ }^{\circ} \mathrm{C}$. The intra-particle diffusion model fitting results indicated that the adsorption of phosphate by CR-LDH was controlled by both liquid membrane

\footnotetext{
* Corresponding author at: School of Environmental and Municipal Engineering, Qingdao University of Technology, Qingdao 266033, PR China.

E-mail address: xxllpp11@126.com (L. P. Xiao); kongqiaoping@qut.edu.cn (Q. P. Kong)
} 
diffusion and intra-particle diffusion. Phosphate was bound to CR-LDH via synergistic effect of physical adsorption, ion exchange, anion intercalation and chemical precipitation as evidenced from a combination of microscopic analysis and adsorption mechanism study. The actual phosphate-containing wastewater investigation showed that CR-LDH not only exhibited good removal effect on phosphate, but also could greatly reduce turbidity, COD and ammonia nitrogen, which was suitable for disposal of practical wastewater. These results indicate that CR-LDH can be considered as potential adsorbent for the treatment of phosphate-containing wastewater, which will be helpful to achieve the goal of "treating waste with waste and turning waste into treasure".

Keywords: Layered double hydroxides; Industrial waste residue; Phosphate; Adsorption; Wastewater

\section{Introduction}

As a non-renewable and irreplaceable resource, phosphorus is essential element for cell growth in plants, animals or bacteria, and thus necessary for maintaining the stability of the whole ecosystem (Jiang et al., 2019; Seftel et al., 2018). However, excess of phosphorous $\left(\geq 0.02 \mathrm{mg} \cdot \mathrm{L}^{-1}\right)$ will cause eutrophication in widespread water body (Yang et al., 2019), along with a series of issues such as the reduction of water economic value and the the restriction of sustainable development of the society and economy. Hence, it's of vital importance for controlling redundant phosphate to a low level by cost-effective approaches (Zhang et al., 2019). Generally speaking, 
41 phosphorus in wastewater usually exists in the main forms of organic phosphate, orthophosphate and polymeric (condensed) phosphate (Bacelo et al., 2020), but the total phosphorus content and the mass fraction of various forms of phosphorus vary depending on the source of the wastewater. Therefore, the most critical step in phosphorus removal of most wastewater is to consider how to remove orthophosphate.

Until now, various approaches have been adopted for the treatment of phosphorus-containing wastewater such as chemical precipitation, crystallization, biological processes and adsorption method (Bacelo et al., 2020). Among them, adsorption with the characteristic of simple operation, low cost and environment-friendly (Kong et al., 2021; Kong et al., 2019) is generally considered to be the most effective method for the treatment of phosphorus-containing wastewater. The key to the popularization and application of adsorption method lies in the research and development of cheap and efficient new adsorbents. Many kinds of adsorbents such as layered double hydroxides (LDHs) (Dox et al., 2019; Liu et al., 2019; Seftel et al., 2018; Zhang et al., 2019), zeolite (Li et al., 2021; Razmi and Ghasemi-Fasaei, 2018), corn bracts (Jiang et al., 2019), lignite (Samaraweera et al., 2021), aluminum-modified eggshells (Guo et al., 2017), sludge (Tie et al., 2013), MgO nanoparticles biochar composites (Zhu et al., 2021) and paper mill sludge-based calcium-containing porous biochar (Wang et al., 2021) have been reported for the removal of phosphorus from wastewater.

LDHs, also known as anionic clays, include hydrotalcite and hydrotalcite like 
compounds, and the main body of LDHs is generally composed of hydroxides of two metals. LDHs have the properties of ion exchange between layers and permanent positive charge. After calcination, the product of LDHs has a huge specific surface area and can return to the original layered structure in a certain environment. LDHs is deemed as an excellent adsorbent for the removal of organic and inorganic pollutants from wastewater. In terms of phosphate removal, Zhang et al. successfully synthesized layered double hydroxides with nitrate via co-precipitation method and the experimental results showed that the multilayer structure of the synthesized LDHs exhibited good adsorption ability towards phosphate (Zhang et al., 2021). Jia et al. exfoliated and incorporated MgAlFe-LDHs in polyether sulfone membranes and the adsorption rate of the obtained membranes was faster than the un-exfoliated one. The adsorption capacity of obtained membranes with respect to phosphate was $5.61 \mathrm{mg} \cdot \mathrm{g}^{-1}$ (Jia et al., 2018). Seftel et al. used modified ZnAl-LDHs to adsorb phosphate from aqueous solutions. The results showed that anionic exchange was the main adsorption mechanism for the phosphate adsorbed by non-calcined LDH, while the adsorption process of LDO materials towards phosphate was attributed to structural reconstruction and precipitation (Seftel et al., 2018). However, the LDHs used in most of the above publications were synthesized using chemical agents. If LDHs can be prepared from industrial waste, the production cost of adsorbent will be greatly reduced and the industrial waste can be reused for recycling. To our best knowledge, the literature focus on using industrial waste residue to prepare LDHs for the removal of phosphate from wastewater had rarely been reported. 
The purpose of this study is to make full use of industrial waste residues to develop new adsorbent for the removal phosphate in wastewater, which can reduce the environmental pollution caused by industrial waste residues, and achieve the purpose of effective treatment of phosphate-containing wastewater. Herein, we prepared a novel CR-LDH adsorbent with hydrocalumite and magnesia structure by calcium carbide slag and red mud via a simple method. Calcium carbide slag is a calcium-containing solid industrial waste residue produced during the hydrride process of chlor-alkali industry, and the main chemical components are $\mathrm{CaO}, \mathrm{Al}_{2} \mathrm{O}_{3}$, $\mathrm{Fe}_{2} \mathrm{O}_{3}, \mathrm{SiO}_{2}, \mathrm{MgO}$, etc. Red mud is a kind of solid waste residue in aluminum industry formed from bauxite (Hu et al., 2017). The influencing factors of adsorbent's dosage, $\mathrm{pH}$ and co-existing ions on the removal performance of phosphate were discussed. The adsorption kinetics, isotherm and thermodynamics were systematically studied. The adsorption mechanism was proposed by combining the experimental investigation and characterization of CR-LDH before and after adsorption of phosphate. In addition, the applicability of CR-LDH for the removal of phosphate in practical phosphate-containing wastewater was also investigated.

\section{Materials and methods}

\subsection{Chemicals and materials}

The carbide slag was taken from an acetylene plant in Fuxin City, Liaoning Province. The red mud was provided by an aluminum plant in Liaocheng City, Shandong Province. The red mud used in this study is "Bayer 
red mud" which accounts for more than $90 \%$ of the world's total red mud. The raw carbide slag and red mud were crushed and ground through 200 mesh sieve, and then dried to constant weight in $105{ }^{\circ} \mathrm{C}$ oven to remove the moisture and maintain the original properties of the materials. The picture of raw calcium carbide slag powder and red mud powder are presented in Fig. S1a and Fig. S1b of Supplementary Material, respectively. The chemical composition of raw calcium carbide slag powder and red mud powder are provided in Table S1 and Table S2. Potassium dihydrogen phosphate $\left(\mathrm{KH}_{2} \mathrm{PO}_{4}\right)$ was purchased from Liaoning Quanrui Reagent Co., Ltd. 100 $\mathrm{mg} \cdot \mathrm{L}^{-1}$ phosphorus standard solution (GSB04-1741-2004a) was supplied by China's national center for analysis and testing of nonferrous metals and electronic materials. Ascorbic acid were purchased from Liaoning Quanrui Reagent Co., Ltd, China. The other chemicals were purchased from Shenyang Huadong Reagent Factory, China. All chemicals were of analytic grade (or higher), and were used without further purification.

\subsection{Preparation of CR-LDH}

The CR-LDH was prepared as the following steps: firstly, the raw material of calcium carbide slag and red mud were roasted at $600{ }^{\circ} \mathrm{C}$ for $3 \mathrm{~h}$ in muffle furnace, respectively. After cooling to room temperature, the obtained calcium carbide slag and red mud with mass ratio of 1:1 were fully mixed and then added into $300 \mathrm{~mL}$ deionized water. Under mechanical stirring of $700 \mathrm{r} \cdot \mathrm{min}^{-1}$, the resulting slurry was stirred at $45{ }^{\circ} \mathrm{C}$ for $3 \mathrm{~h}$. Subsequently, the above mixture was crystallized in $70{ }^{\circ} \mathrm{C}$ 
water bath for $24 \mathrm{~h}$ and the residue was washed thoroughly with distilled water. After drying at $105{ }^{\circ} \mathrm{C}$ to constant weight, the precipitate was ground to pass through 200-mesh sieve. Finally, carbide slag red mud composite powder was obtained, denoted as CR-LDH. The picture of the prepared of CR-LDH was shown in Fig. S2.

\subsection{Physicochemical characteristic of CR-LDH}

The morphology and element distribution of CR-LDH was determined by a S-4800 scanning electron microscopy (SEM) (Hitachi, Japan) and energy-dispersive spectroscopy (EDS) mapping analysis. To determine the surface area of CR-LDH, a ASAP2460 Brunauer-Emmett-Teller $\mathrm{N}_{2}$ adsorption analysis (BET) (Micromeritics, USA) was used. The functional groups and chemical bond types of CR-LDH from 4000 to $400 \mathrm{~cm}^{-1}$ was measured by a NICOLET iS5 fourier transform infrared spectroscopy (FT-IR) (Thermo Nicolet Corporation, USA). A X'pert pro X-ray diffraction (XRD) (Spectris, Holland) with $\mathrm{Cu} \mathrm{K}^{\alpha}$ radiation (40 $\mathrm{kV}, 40 \mathrm{~mA}$ ) at a scan speed of $4^{\circ} \cdot \mathrm{min}^{-1}$ was used to detect the crystallographic structure of CR-LDH.

\subsection{Batch adsorption experiments of CR-LDH}

A series of batch adsorption tests were conducted to evaluate the adsorption performance of CR-LDH with respect to phosphate. The adsorption experiments were carried out in $250 \mathrm{~mL}$ conical flasks with a certain amount of CR-LDH and $100 \mathrm{~mL}$ of phosphate at $25{ }^{\circ} \mathrm{C}$. After adsorption equilibrium, the supernatants were collected and then filtered through $0.45 \mu \mathrm{m}$ membrane filter and diluted for further phosphate analysis by the UV spectrophotometer at a wavelength 
151

$152 \mathrm{pH}$ values of the phosphate solutions were adjusted by $0.1 \mathrm{~mol} \cdot \mathrm{L}^{-1} \mathrm{HNO}_{3}$ or $\mathrm{NaOH}$.

153 The adsorption kinetics of phosphate were carried out by immersing $0.5 \mathrm{~g}$ of CR-LDH

154 into $100 \mathrm{~mL}$ phosphate solution with concentration of $30 \mathrm{mg} \cdot \mathrm{L}^{-1}\left(25^{\circ} \mathrm{C}, 10 \mathrm{~h}\right)$. For the

155 adsorption isotherms study, $0.5 \mathrm{~g}$ of CR-LDH was added into $100 \mathrm{~mL}$ of phosphate

156 solution with initial concentration ranging from 5 to $210 \mathrm{mg} \cdot \mathrm{L}^{-1}$ by maintaining

157 reaction temperature at at $15,25,35^{\circ} \mathrm{C}$, respectively. The adsorption amount and

removal efficiency of CR-LDH towards phosphate were calculated by the following equations:

$$
\begin{gathered}
\mathrm{Q}_{\mathrm{t}}=\frac{\left(\mathrm{C}_{0}-\mathrm{C}_{\mathrm{t}}\right) \mathrm{V}}{\mathrm{m}} \\
\text { Removal efficiency }=\frac{\left(\mathrm{C}_{0}-\mathrm{C}_{\mathrm{t}}\right)}{\mathrm{C}_{0}} \times 100 \%
\end{gathered}
$$

where $\mathrm{Q}_{\mathrm{t}}$ is adsorption amount of phosphate onto CR-LDH at time of $\mathrm{t}, \mathrm{mg} \cdot \mathrm{g}^{-1}$;

$\mathrm{C}_{0}$ is the initial concentration of phosphate, $\mathrm{mg} \cdot \mathrm{L}^{-1} ; \mathrm{C}_{\mathrm{t}}$ is the concentration of phosphate at time of $\mathrm{t}$; $\mathrm{m}$ is the mass of $\mathrm{CR}-\mathrm{LDH}, \mathrm{mg} \cdot \mathrm{L}^{-1}$; and $\mathrm{V}$ is the volume of solution, mL.

\section{Results and discussion}

\subsection{Characterization of CR-LDH composites}

The structural characteristics of calcium carbide slag, red mud and CR-LDH are investigated by XRD patterns and the results are shown in Fig. 1. In the spectrum of calcium carbide slag, the peaks at $2 \theta$ values of $18.107^{0}, 28.728^{0}, 34.169^{0}, 47.249^{0}$, $50.896^{\circ}$ and $54.464^{0}$ suggested the presence of $\mathrm{Ca}(\mathrm{OH})_{2}$. The component of $\mathrm{Ca}(\mathrm{OH})_{2}$ 
would be conductive for the removal of phosphate by forming phosphide precipitation through the reaction between $\mathrm{Ca}^{2+}$ and phosphate at high $\mathrm{pH}$ environmental conditions. However, phosphate removal by calcium carbide slag would lead to higher $\mathrm{pH}$ value of effluent. The XRD pattern of red mud presented the absorption peaks of $\mathrm{Fe}_{2} \mathrm{O}_{3}\left(2 \theta=33.117^{0}\right.$ and $\left.2 \theta=35.604^{0}\right), \mathrm{CaO}\left(2 \theta=24.749^{0}\right.$ and $\left.2 \theta=29.756^{0}\right)$ and $\mathrm{SiO}_{2}\left(2 \theta=21.662^{\circ}\right)$. The abundant metal elements in red mud, especially for $\mathrm{Al}$ and $\mathrm{Fe}$, could interact with phosphate during the adsorption process. For XRD patterns of CR-LDH composite, the characteristic peaks corresponding to the (002) and (004) crystal planes of hydrocalumite were appeared, which was consistent with the PDF card of the International Diffraction Data Center (PDF\#16-0333). The CR-LDH composite exhibited hydrocalumite structure. Hydrocalumite was an ordered layered inorganic compound of LDHs with excellent removal ability for phosphate. The diffraction peaks corresponding to the hydrocalumite (002) crystal plane had the characteristics of sharp peaks, good peak type, low and flat base line, high crystallinity and a relatively complete monoclinic symmetrical layered structure. In addition, the characteristic peaks corresponding to the (003) crystal face of boehmite were appeared in the XRD patterns of CR-LDH. The peaks of $\mathrm{CaCO}_{3}\left(2 \theta=43.14^{0}\right)$ and $\mathrm{Fe}_{2} \mathrm{O}_{3}\left(2 \theta=33.24^{0}, 2 \theta=35.73^{\circ}\right.$ and $\left.2 \theta=54.21^{\circ}\right)$ were also detected in the XRD patterns of CR-LDH. The reason for the existence of these metal oxides was that their raw materials are industrial waste slag, and the metal oxides were not fully reacted in the process of preparing the composites, and there were still some metal oxides in the CR-LDH composite. All these findings indicated that calcium carbide slag and red 
193

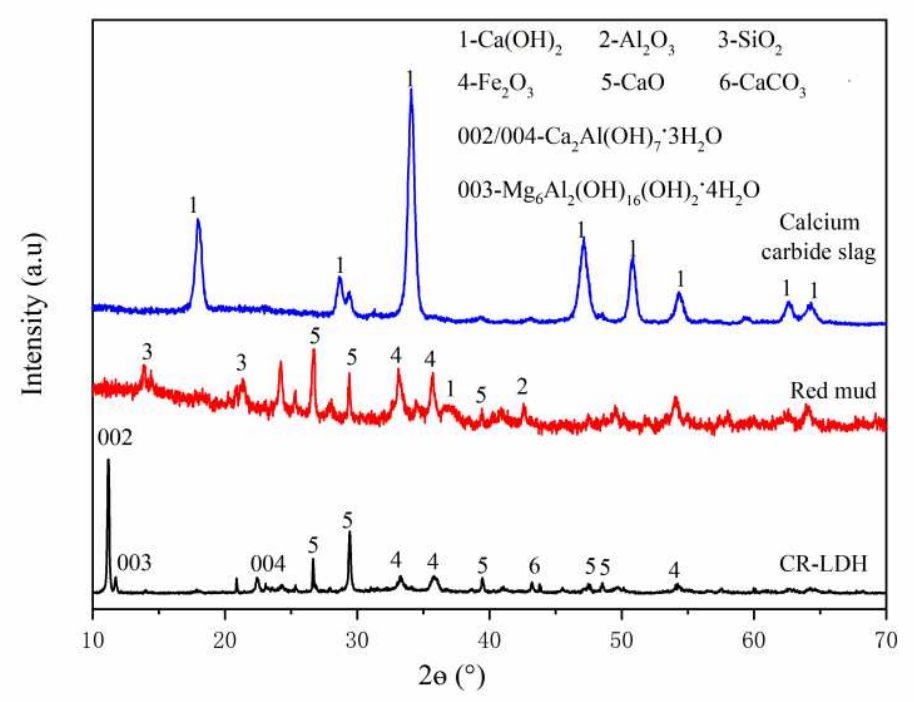

Fig. 1 XRD pattern of calcium carbide slag, red mud and CR-LDH.

SEM and EDS are used to investigate the surface morphology and element content distribution of CR-LDH, respectively. As shown in Fig. 2a and Fig. 2b, CR-LDH presented a typical plate-like morphology of LDHs (Cheng et al., 2019). The surface of CR-LDH was relatively rough and there are a large number of gaps, which was conducive to the adsorption process. The BET surface area of CR-LDH was $42.46 \mathrm{~m}^{2} \cdot \mathrm{g}^{-1}$, providing a large number of surface active sites for the adsorption of phosphate in the aqueous solutions. According to the EDS results (Fig. 2c and Table 1), the content ratio of main elements of $\mathrm{CR}$ LDHs mainly contained $\mathrm{O}, \mathrm{Al}$ and $\mathrm{Ca}$, and the content of $\mathrm{Ca}$ was much higher than that of other metal elements, which were consistent with the XRD results that CR-LDH had the characteristic adsorption peaks of hydrocalumite and boehmite. 

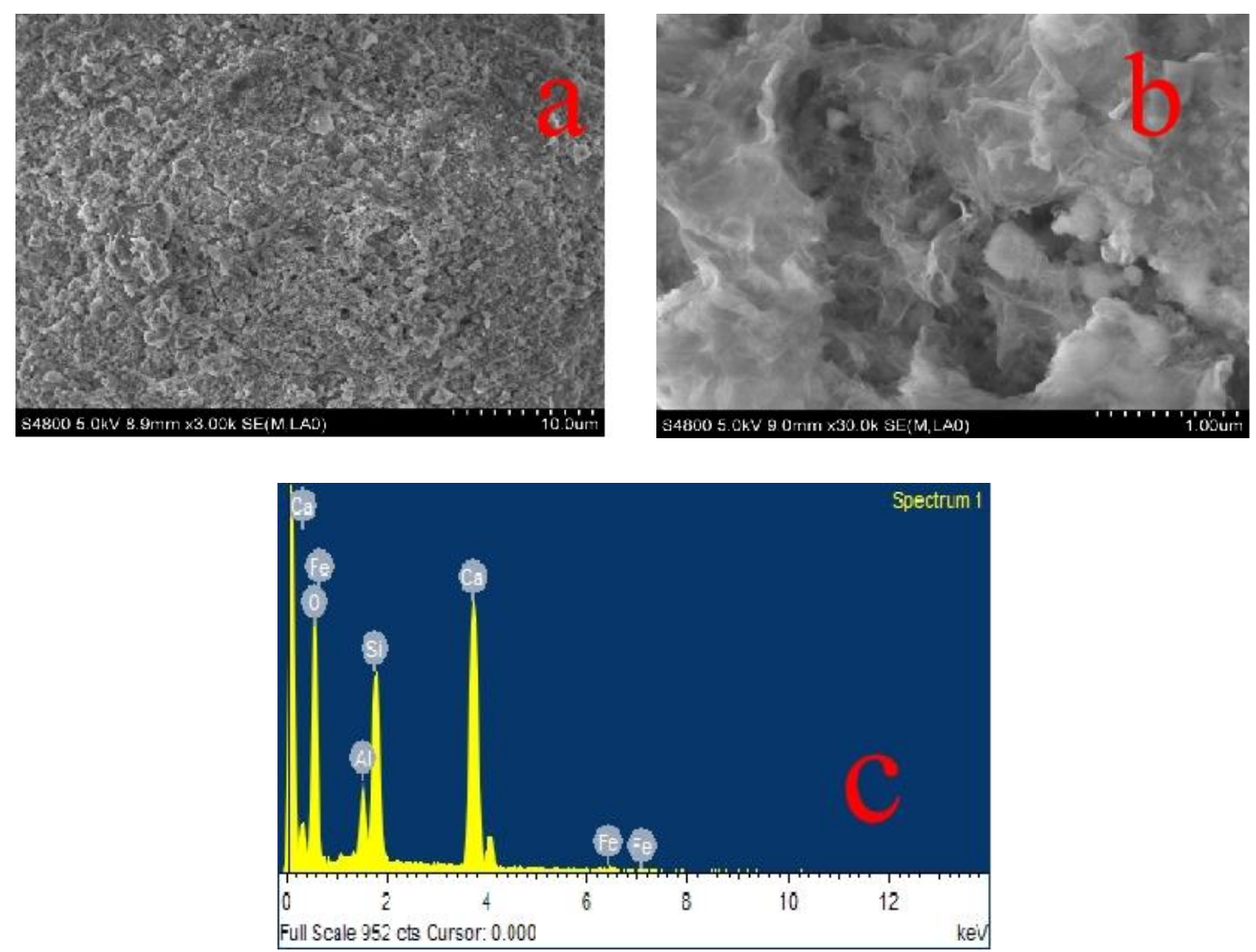

Fig. 2 SEM of CR-LDH (a, b) and EDS of CR-LDH (c).

Table 1 The elemental content changes of CR-LDH before and after adsorption of phosphate.

\begin{tabular}{|c|c|c|c|c|}
\hline \multirow[t]{2}{*}{ Element } & \multicolumn{2}{|c|}{ CR-LDH（Before adsorption） } & \multicolumn{2}{|c|}{ CR-LDH-phosphate (After } \\
\hline & wt $\%$ & at $\%$ & wt $\%$ & at $\%$ \\
\hline $\mathrm{O}$ & 62.35 & 78.42 & 47.30 & 69.23 \\
\hline $\mathrm{Al}$ & 3.26 & 2.43 & 7.49 & 6.50 \\
\hline $\mathrm{Si}$ & 9.30 & 6.67 & 4.54 & 3.79 \\
\hline $\mathrm{Ca}$ & 24.24 & 12.17 & 14.89 & 8.70 \\
\hline $\mathrm{Fe}$ & 0.85 & 0.31 & 20.82 & 8.73 \\
\hline
\end{tabular}




\begin{tabular}{cllll}
\hline $\mathrm{P}$ & - & - & 1.20 & 0.91 \\
\hline
\end{tabular}

\subsection{Optimization of the batch adsorption conditions}

\subsubsection{Effect of CR-LDH daosage on phosphate adsorption}

To investigate the effect of dosage on the adsorption performance of CR-LDH with respect to phosphate, $0.5,1,2,3,4,5$ and $6 \mathrm{~g} \cdot \mathrm{L}^{-1} \mathrm{CR}-\mathrm{LDH}$ were added into 100 $\mathrm{mL}$ phosphate ion solution with a concentration $30 \mathrm{mg} \cdot \mathrm{L}^{-1}$. Adsorption experiments conducted for $24 \mathrm{~h}$ at $25^{\circ} \mathrm{C}$ with $\mathrm{pH}$ of 7 and shaking speed of $180 \mathrm{r} \cdot \mathrm{min}^{-1}$. The results are shown in Fig. 3a. It can be seen from Fig. 3a that the removal rate of phosphate was first gradually increased and then basically approached $100 \%$, while the adsorption ability of per unit mass CR-LDH was gradually decreased. The increase of phosphate removal rate was due to the increase of adsorbent dosage, which increases the number of available adsorption sites on the material surface and the contact probability with adsorption sites in the solution, providing favorable conditions for phosphate adsorption removal. Under the condition that the initial concentration of phosphate is $30 \mathrm{mg} \cdot \mathrm{L}^{-1}$, the amount of phosphate in solution was fixed and more phosphate were removed with the increasing dosage of CR-LDH, while the per amount phosphate adsorbed by CR-LDH was decreased relatively. Considering the phosphate removal performance and meeting the first-level discharge standard $\left(\leq 0.5 \mathrm{mg} \cdot \mathrm{L}^{-1}\right)$ in the comprehensive sewage discharge standard of China (GB8978-1996), the optimal dosage of $5 \mathrm{~g} \cdot \mathrm{L}^{-1}$ was selected in the following study when the phosphate concentration was $30 \mathrm{mg} \cdot \mathrm{L}^{-1}$. Under this condition, the phosphate removal rate was $98.6 \%$ and the phosphate concentration in the effluent was 0.42 

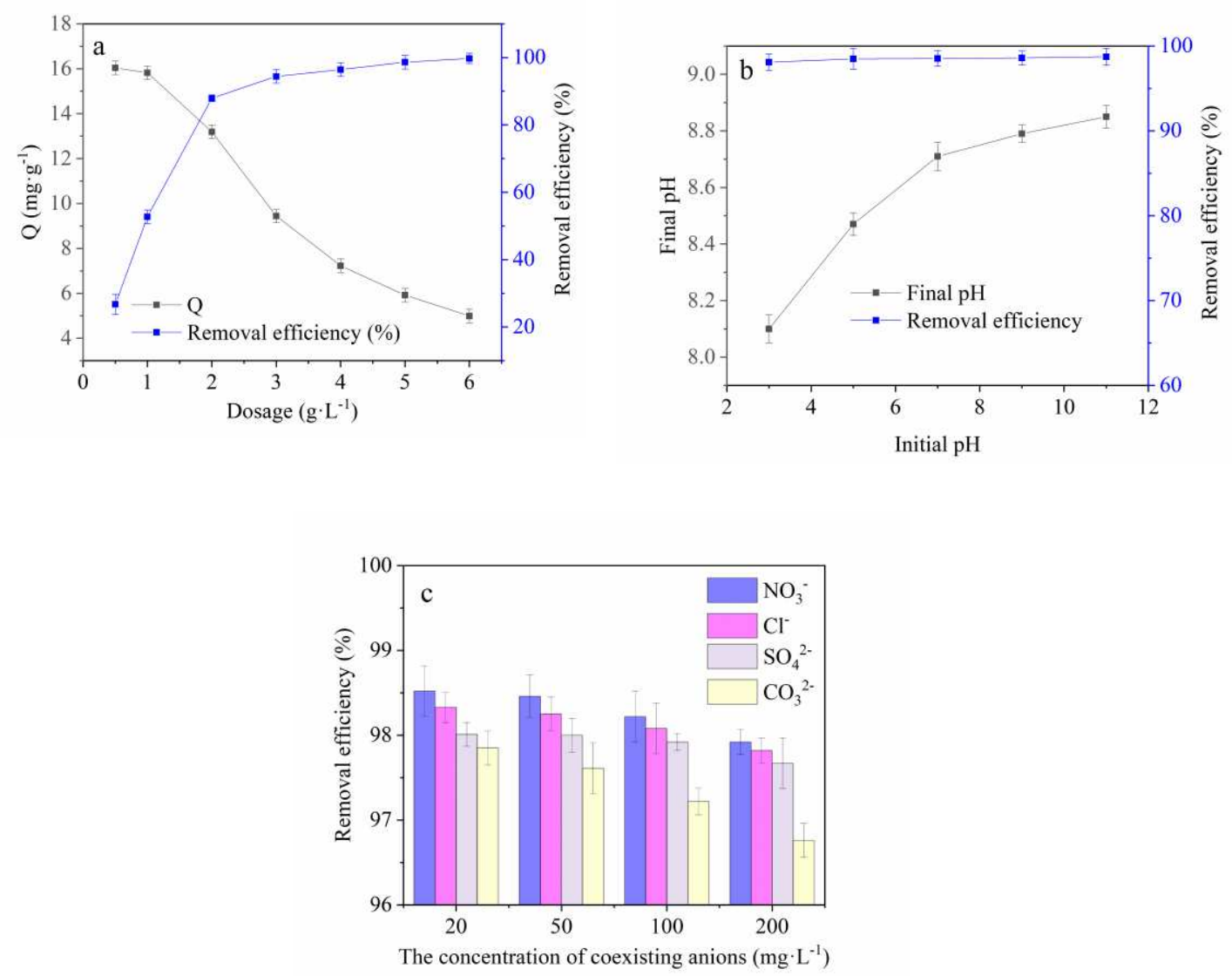

231 Fig. 3 Adsorption performance of CR-LDH towards phosphate as a function of CR-LDH dosage (a), initial pH (b) and of coexisting anions (c).

\subsubsection{Effect of initial $\mathrm{pH}$ values on phosphate adsorption} reaction process of adsorbent towards adsorbate because $\mathrm{pH}$ will influence the phosphate dissociation equilibria in aqueous solutions (Cheng et al., 2009; Kong et al., 2020; Zhang et al., 2019):

$$
\mathrm{H}_{3} \mathrm{PO}_{4} \stackrel{\mathrm{K}_{1}}{\longleftrightarrow} \mathrm{H}_{2} \mathrm{PO}_{4}^{-}+\mathrm{H}^{+} \stackrel{\mathrm{K}_{2}}{\longleftrightarrow} \mathrm{HPO}_{4}{ }^{2-}+2 \mathrm{H}^{+} \stackrel{\mathrm{K}_{3}}{\longleftrightarrow} \mathrm{PO}_{4}^{3-}+3 \mathrm{H}^{+}
$$


ranging from 3.0 to 11.0 and the results were shown in Fig. 3b. As shown in Fig. 3b, with the increase of initial $\mathrm{pH}$, the phosphate removal rate increased gradually, but the change range was relatively small. When the $\mathrm{pH}$ was in the range of 3.0-11.0 (the main species of phosphate was $\mathrm{H}_{2} \mathrm{PO}_{4}^{-}$and $\mathrm{HPO}_{4}{ }^{2-}$, , CR-LDH maintained a high phosphate removal rate. Due to the adsorption free energy of $\mathrm{H}_{2} \mathrm{PO}_{4}{ }^{-}$was lower than that of $\mathrm{HPO}_{4}{ }^{2-}$ (Yang et al., 2014), so CR-LDH was more likely to adsorb $\mathrm{H}_{2} \mathrm{PO}_{4}^{-}$. At $\mathrm{pH} 3.0$ and 11.0, the phosphate removal rate were $98.1 \%$ and $98.7 \%$, respectively. This phenomenon is mainly due to that CR-LDH have a certain regulating effect on the $\mathrm{pH}$ of the solution. The final $\mathrm{pH}$ values were gradually increased after reaction equilibrium and remained ranging from 8.1 to 8.9 , indicating that $\mathrm{OH}^{-}$were released by CR-LDH in the adsorption process under lower $\mathrm{pH}$. While at higher $\mathrm{pH}$ values, $\mathrm{OH}^{-}$was consumed in the transformation process of calcium phosphate precipitation into hydroxyapatite. Considering that the actual water samples are mostly in the neutral range, $\mathrm{pH}$ of 7.0 was selected in the follow-up experiments.

\subsubsection{Effect of co-existing inorganic anions on phosphate adsorption}

Phosphate is not existed alone in wastewater, but may be coexisted with $\mathrm{CO}_{3}{ }^{2-}$, $\mathrm{SO}_{4}{ }^{2-}, \mathrm{NO}_{3}{ }^{-}, \mathrm{Cl}^{-}$and other inorganic anions. In this study, the effect of $\mathrm{CO}_{3}{ }^{2-}, \mathrm{SO}_{4}{ }^{2-}$, $\mathrm{NO}_{3}{ }^{-}, \mathrm{Cl}^{-}$on the adsorption performance of $\mathrm{CR}-\mathrm{LDH}$ towards phosphate were investigated within co-existing inorganic anions concentration of 20, 50, 100 and 200 $\mathrm{mg} \cdot \mathrm{L}^{-1}$, respectively. As shown in Fig. 3c, when $\mathrm{CO}_{3}{ }^{2-}, \mathrm{SO}_{4}{ }^{2-}, \mathrm{NO}_{3}{ }^{-}, \mathrm{Cl}^{-}$were con-existed in solution, the removal rate of phosphate was deceased in varying degrees. The inhibition effect of co-existing inorganic anions was increased with the 
increase of its concentration. Under the same initial concentration of $\mathrm{CO}_{3}{ }^{2-}, \mathrm{SO}_{4}{ }^{2-}$, $\mathrm{NO}_{3}{ }^{-}, \mathrm{Cl}^{-}$, the inhibition order of the above four co-existing ions was as follows: $\mathrm{CO}_{3}{ }^{2-}>\mathrm{SO}_{4}{ }^{2-}>\mathrm{Cl}^{-}>\mathrm{NO}_{3}{ }^{-}$. When the concentration of $\mathrm{CO}_{3}{ }^{2-}$ was $200 \mathrm{mg} \cdot \mathrm{L}^{-1}$, the removal rate of CR-LDH towards phosphate was reduced to $96.77 \%$ and the effluent phosphate concentration was $0.97 \mathrm{mg} \cdot \mathrm{L}^{-1}$. The inhibition effect of co-existing inorganic anions was mainly due to the fact that these anions would compete with phosphate to enter the interlayer structure of CR-LDH in adsorption process, resulting in decrease adsorption sites of the interlayer. The interaction between the inorganic anions with higher valence and the positively charged laminates was stronger, which made it easier to enter the interlayer channels of CR-LDH. As a result, the inhibitory effect of bivalent anion $\left(\mathrm{CO}_{3}{ }^{2-}\right.$ and $\left.\mathrm{SO}_{4}{ }^{2-}\right)$ were stronger than that of monovalent anion $\left(\mathrm{NO}_{3}{ }^{-}\right.$and $\left.\mathrm{Cl}^{-}\right)$, which was consistent with the research results reported in previous publications (Seftel et al., 2018).

\subsubsection{Adsorption kinetics}

The process of phosphate adsorbed by CR-LDH is a time-dependent reaction. The adsorption behavior of CR-LDH with respect to phosphate as a function of time was studied and the results were shown in Fig. 4. It can be seen that the adsorption of phosphate by CR LDHs can be roughly divided into three stages, namely, the rapid adsorption reaction stage of $0-60 \mathrm{~min}$, the slow adsorption reaction stage of $60-480$ min, and the adsorption equilibrium stage after $480 \mathrm{~min}$. At the initial stage of adsorption, the surface of CR-LDH possessed abundant adsorption sites and a large number of phosphate were existed in the solution, leading to the faster adsorption rate 

phosphate was decreased in the solution and numerous adsorption site on the surface of CR-LDH were occupied by phosphate. As a result, the available adsorption sites of

CR-LDH were less and the adsorption rate of phosphate was decreased accordingly.
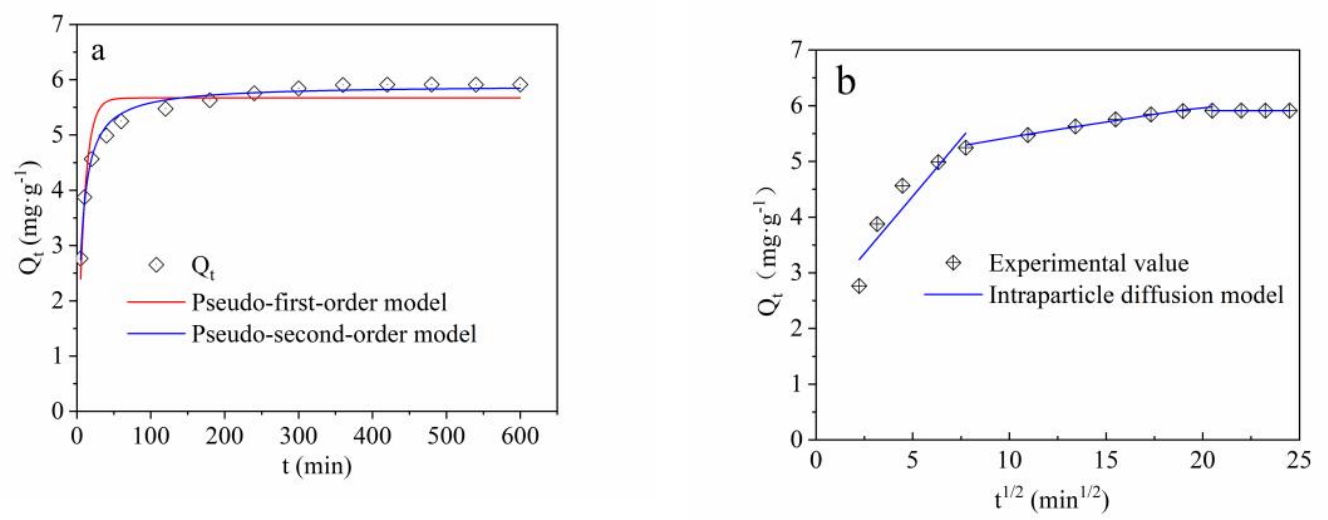

289

290

291

292

293

294

Fig. 4 Fitting results of pseudo-first-order, pseudo-second-order kinetic model (a) and intra-particle diffusion model (b).

To better describe the adsorption process of CR-LDH towards phosphate, pseudo-first-order, pseudo-second-order and intra-particle diffusion kinetic models were adopted in this study. The pseudo-first-order and pseudo-second-order equations are expressed as Eq. (3) and Eq. (4), respectively.

$$
\begin{gathered}
\mathrm{Q}_{\mathrm{t}}=\mathrm{Q}_{\mathrm{e}}\left(1-\mathrm{e}^{-\mathrm{k}_{1} \mathrm{t}}\right) \\
\mathrm{Q}_{\mathrm{t}}=\frac{\mathrm{Q}_{\mathrm{e}}{ }^{2} \mathrm{k}_{2} \mathrm{t}}{1+\mathrm{Q}_{\mathrm{e}} \mathrm{k}_{2} \mathrm{t}}
\end{gathered}
$$

where $\mathrm{t}(\mathrm{min})$ represents the adsorption time; $\mathrm{Q}_{\mathrm{t}}$ is the adsorption amount of phosphate adsorbed by CR-LDH at time $\mathrm{t}, \mathrm{mg} \cdot \mathrm{g}^{-1}$; $\mathrm{Q}_{\mathrm{e}}$ represents the equilibrium adsorption capacity, $\mathrm{mg} \cdot \mathrm{g}^{-1} ; \mathrm{k}_{1}\left(\mathrm{~min}^{-1}\right)$ and $\mathrm{k}_{2} \quad\left(\mathrm{~g} \cdot \mathrm{mg}^{-1} \cdot \mathrm{min}^{-1}\right)$ donate the pseudo-first-order and pseudo-second-order rate constants, respectively. As illustrated 
299 in Fig. 4a and Table 2, the pseudo-second-order kinetic model $\left(\mathrm{R}^{2}=0.989\right)$ better fitted 300 than the pseudo-second-order kinetic model $\left(\mathrm{R}^{2}=0.896\right)$ for phosphate adsorption on 301 CR-LDH, suggesting that the adsorption of phosphate onto CR-LDH was mainly 302 controlled by chemical adsorption through sharing or exchanging electrons, thus 303 forming valence force for adsorption (Cao et al., 2020).

To determine the adsorption rate limiting step, intra-particle diffusion model was used to fitting the adsorption experimental results. The intra-particle diffusion model can be expressed as follows:

$$
\mathrm{Q}_{\mathrm{t}}=\mathrm{k}_{3} \mathrm{t}^{1 / 2}+\mathrm{C}
$$

where $\mathrm{k}_{3}$ represents the intra-particle diffusion rate constant $\left(\mathrm{mg} \cdot\left(\mathrm{g} \mathrm{min}{ }^{1 / 2}\right)^{-1}\right)$ and $\mathrm{C}$ is the constant related to the thickness of the boundary layer $\left(\mathrm{mg} \cdot \mathrm{g}^{-1}\right)$. Table 2 Fitting results of kinetic model.

\begin{tabular}{ccc}
\hline Kinetic model & Parameter & Value \\
\hline Pseudo-first-order kinetic & $\mathrm{Q}_{\mathrm{e}}$ & 5.67 \\
model & $\mathrm{k}_{1}$ & 0.10967 \\
& $\mathrm{R}^{2}$ & 0.896 \\
Pseudo-second-order & $\mathrm{Q}_{\mathrm{e}}$ & 5.90 \\
kinetic model & $\mathrm{K}_{2}$ & 0.0293 \\
& $\mathrm{R}^{2}$ & 0.989 \\
& $\mathrm{C}$ & 2.3151 \\
& $\mathrm{R}_{1}{ }^{2}$ & 0.8689
\end{tabular}




$\begin{array}{ll}\mathrm{C} 2 & 4.8779 \\ \mathrm{k}_{32} & 0.0538 \\ \mathrm{R}_{2}^{2} & 0.970 \\ \mathrm{C} 3 & 5.9009 \\ \mathrm{k}_{33} & 0.0005 \\ \mathrm{R}_{3}{ }^{2} & 0.6439\end{array}$

According to intra-particle diffusion kinetic model, if the adsorption rate is only

311 determined by the intra-particle diffusion, the $\mathrm{Q}_{\mathrm{t}}-\mathrm{t}^{1 / 2}$ curve will be a straight line with

$312 \mathrm{C}$ value of zero. As shown in Fig. $4 \mathrm{~b}$ and Table 2, the adsorption experimental results

313 of CR-LDH towards phosphate presented a linear relationship in three stages and 314 value of $\mathrm{C}$ was not zero, suggesting that intra-particle diffusion was not the solely 315 speed limiting step. The adsorption process of CR-LDH with respect to phosphate 316 could be divided into three stages: film diffusion stage, intra-particle diffusion stage 317 and adsorption equilibrium stage. The film diffusion stage which occurred on the 318 initial of the reaction of $0-60$ min was a rapid adsorption stage. Phosphate could 319 transfer to the abundant adsorption sites on the surface of CR-LDH through film 320 diffusion to achieve rapid adsorption. The intra-particle diffusion stage happened on $32160-480$ min was a gradual adsorption stage. In this stage, phosphate reached the 322 adsorption sites inside the pores of the CR-LDH with the happening of intra-particle 323 diffusion. The third stage was adsorption equilibrium stage (>480 $\mathrm{min})$ and the 324 adsorption driving force was relatively weak due to the fact that there were fewer 325 adsorption sites in the solution and the number of free phosphate radicals was very 
limited. The obtained $\mathrm{C}$ value followed the sequence of $\mathrm{C}_{1}<\mathrm{C}_{2}<\mathrm{C}_{3}$, indicating that the

327 boundary layer thickness of CR-LDH was increased with the proceed of adsorption 328 reaction of CR-LDH towards phosphate.

329

330

331

332

333

334

\subsubsection{Adsorption isotherms}

Adsorption isotherms of phosphate removed by CR-LDH were investigated within different concentration of phosphate ranging from 0 to $150 \mathrm{mg} \cdot \mathrm{L}^{-1}$ at three different temperatures $\left(15,25\right.$ and $\left.35{ }^{\circ} \mathrm{C}\right)$ and the results were shown in Fig. 5. As exhibited in Fig. 5, with the increasing of phosphate's initial concentration, the adsorption capacity of CR-LDH towards phosphate was increased. When the initial concentration of phosphate was at a relatively low level, the adsorption sites on CR-LDH could ensure that most of the phosphate in the solution was removed, and the corresponding phosphate adsorption capacity of CR-LDH showed a linear upward trend. With the further increase of the initial phosphate concentration, more and more adsorption sites were occupied by phosphate radicals, and the number of free adsorption sites was decreased, leading to the decrease in the tangent slope of the phosphate adsorption curve. 
342

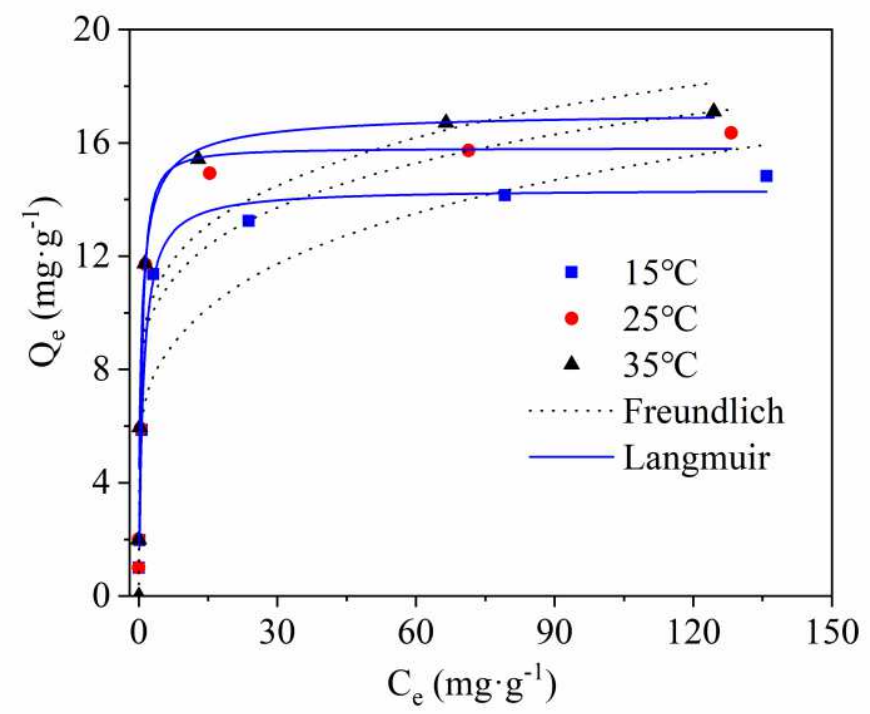

Fig. 5 Isotherms of phosphate adsorption on CR-LDH.

Langmuir and Freundlich isotherm models were conducted to simulate the adsorption experimental data of phosphate adsorbed by CR-LDH. The equation of Langmuir (chemical adsorption model of single molecular layer) and Freundlich (empirical model) isotherm models can be expressed as (Kong et al., 2019):

$$
\begin{aligned}
\mathrm{Q}_{\mathrm{e}} & =\frac{\mathrm{Q}_{\max } \mathrm{bC}_{\mathrm{e}}}{1+\mathrm{bC}_{\mathrm{e}}} \\
\mathrm{Q}_{\mathrm{e}} & =\mathrm{K}_{\mathrm{F}} \mathrm{C}_{\mathrm{e}}{ }^{1 / n}
\end{aligned}
$$

where $C_{e}$ represents equilibrium concentration of phosphate, $\mathrm{mg} \cdot \mathrm{L}^{-1}$; $\mathrm{Q}_{\max }$ is the maximum adsorption capacity, $\mathrm{mg} \cdot \mathrm{g}^{-1} ; \mathrm{b}$ is the affinity coefficient, $\mathrm{L} \cdot \mathrm{mg}^{-1} ; \mathrm{K}_{\mathrm{F}}$ and $\mathrm{n}$ represent the constants of Freundlich isotherm model.

The fitting results of experimental data of Langmuir and Freundlich isotherm models are exhibited in Fig. 5 and Table 3. Compared to Freundlich isotherm model, Langmuir isotherm model $\left(\mathrm{R}^{2}>0.98\right)$ was more suitable to fit the adsorption process of phosphate adsorbed onto CR-LDH which indicated that the adsorbed phosphate had 


\begin{tabular}{ccccccc}
\hline Temperature & $\mathrm{Q}_{\max }$ & Langmuir & & \multicolumn{3}{c}{ Freundlich } \\
$\left({ }^{\circ} \mathrm{C}\right)$ & $\left(\mathrm{mg} \cdot \mathrm{g}^{-1}\right)$ & $\mathrm{b}$ & $\mathrm{R}^{2}$ & $\mathrm{~K}_{\mathrm{F}}$ & $\mathrm{n}$ & $\mathrm{R}^{2}$ \\
\hline 15 & 14.41 & 1.06 & 0.994 & 6.87 & 5.83 & 0.889 \\
25 & 16.06 & 1.53 & 0.989 & 9.45 & 8.12 & 0.941 \\
35 & 16.59 & 2.19 & 0.993 & 9.97 & 8.07 & 0.955 \\
\hline
\end{tabular}

Table 4 Comparison of the adsorption ability of different LDHs towards phosphate.

no interaction with each other and were distributed on the surface of CR-LDH as a molecular layer. The maximum adsorption capacity values calculated by Langmuir isotherm were close to the experimental data. When the temperature increased from 15 to $35^{\circ} \mathrm{C}$, the maximum adsorption capacity of CR-LDH towards phosphate were enhanced from 14.41 to $16.59 \mathrm{mg} \cdot \mathrm{g}^{-1}$, indicating that high temperature had a beneficial effect on adsorption of phosphate. Comparison of the adsorption ability of different adsorbents towards phosphate is provided in Table 4. It can be seen that the maximum adsorption capacity of CR-LDH was in the middle level. In light of the cost of the adsorbent and the reuse of industrial waste-carbide slag, CR-LDH is still considered as a potential environmental friendly adsorbent. The $\mathrm{n}$ values of Freundlich isotherm model were all higher than 1, suggesting that the adsorption process of CR-LDH with respect to phosphate was easily implemented.

Table 3 Isotherm fitting results of phosphorus removal by CR-LDH.
Adsorbents

\begin{tabular}{ccc}
\hline & Maximum adsorption & \\
Adsorbents & References \\
& amount $\left(\mathrm{mg} \cdot \mathrm{g}^{-1}\right)$ & \\
\hline $\mathrm{Zn}-\mathrm{Al} \mathrm{LDH}$ & 41.26 & (Cheng et al., 2010)
\end{tabular}


Mg-Al LDH

Zn-Al LDH

Calcined MgMn-LDHs

Mg-Al LDH (granular)

CR-LDH
68.40

16.06
(Yang et al., 2014)

(Yang et al., 2014)

(Chitrakar et al., 2005)

(Kuzawa et al., 2006)

This study
369

370

371

372

373

374

37

376

377

378

\subsubsection{Adsorption thermodynamics}

Adsorption thermodynamics analysis were also carried out to describe the adsorption process of phosphate adsorbed by CR-LDH. The adsorption thermodynamics formula can be expressed as follows:

$$
\begin{gathered}
\Delta \mathrm{G}^{0}=-\mathrm{RT} \ln \mathrm{K}^{0} \\
\ln \mathrm{K}^{0}=\frac{\Delta \mathrm{S}^{0}}{\mathrm{R}}-\frac{\Delta \mathrm{H}^{0}}{\mathrm{RT}}
\end{gathered}
$$

where $\Delta \mathrm{G}^{0}$ is the Gibbs free energy, $\mathrm{KJ} \cdot \mathrm{mol}^{-1}$; R represents the is the constant of perfect gas and $\mathrm{R}=8.314 \mathrm{~J} \cdot \mathrm{mol}^{-1} \cdot \mathrm{K}^{-1} ; \mathrm{T}$ is the absolute temperature of solution, $\mathrm{K} ; \Delta \mathrm{S}^{0}$ represents the entropy change, $\mathrm{J} \cdot \mathrm{mol}^{-1} \cdot \mathrm{K}^{-1} ; \Delta \mathrm{H}^{0}$ is the enthalpy change, $\mathrm{KJ} \cdot \mathrm{mol}^{-1}$ and $\mathrm{K}^{0}$ is the standard equilibrium constant. Because the adsorption process of CR-LDH with respect to phosphate fitted Langmuir isotherm model well with $\mathrm{R}^{2}>0.98$, so the Langmuir constant of $\mathrm{b}$ could be calculated as $\mathrm{K}^{0}$. 
379

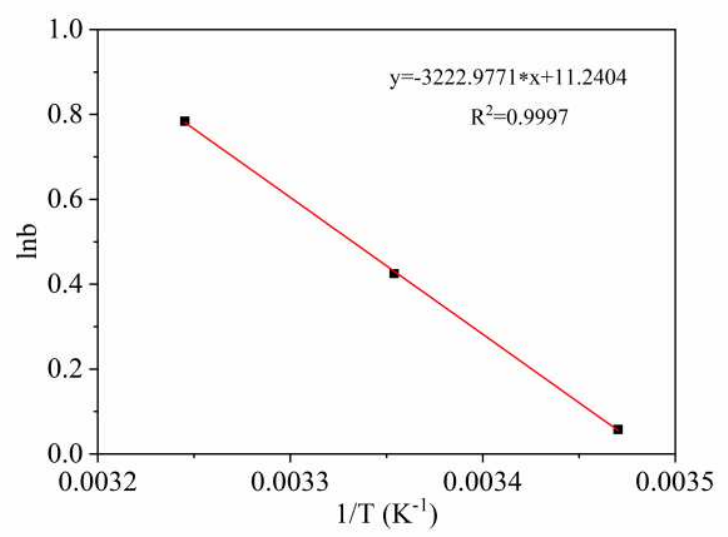

Fig. 6 lnb and 1/T relationship curve of CR-LDH adsorption phosphorus.

As shown in Fig. 6 and Table 5, the values of $\Delta G^{0}$ were all less than zero which suggested the adsorption process of phosphate by CR-LDH were spontaneous reaction.

The absolute values of $\Delta \mathrm{G}^{0}$ became more positive with the increasing of temperature, suggesting that higher temperature was more conductive to the adsorption of CR-LDH towards phosphate. The positive $\Delta \mathrm{H}^{0}$ of $26.21 \mathrm{KJ} \cdot \mathrm{mol}^{-1}$ implied that the adsorption of phosphate by CR-LDH were endothermic and this finding was in agreement with the results that the adsorption capacities of CR-LDH were enhanced with the increasing of temperature. The positive $\Delta \mathrm{S}^{0}$ of $91.45 \mathrm{~J} \cdot \mathrm{mol}^{-1} \cdot \mathrm{K}^{-1}$ indicated that the randomness at the solid-solution interface was increased which was due to the adsorption reaction of phosphate adsorbed by CR-LDH.

Table 5 Thermodynamic results of phosphorus adsorbed by CR-LDH.

\begin{tabular}{cccc}
\hline Temperature $(\mathrm{K})$ & $\Delta \mathrm{G}\left(\mathrm{KJ} \cdot \mathrm{mol}^{-1}\right)$ & $\Delta \mathrm{H}\left(\mathrm{KJ} \cdot \mathrm{mol}^{-1}\right)$ & $\triangle \mathrm{S}\left(\mathrm{J} \cdot \mathrm{mol}^{-1} \cdot \mathrm{K}^{-1}\right)$ \\
\hline 288.15 & -0.140 & & \\
298.15 & -1.054 & 26.21 & \\
308.15 & -2.008 & & \\
\hline
\end{tabular}




\subsubsection{Application of CR-LDH to practical phosphate-containing wastewater}

To investigate the applicability of CR-LDH for the removal of phosphate in practical phosphate-containing wastewater, the untreated wastewater in the sewage well of a machinery factory in Shenyang is selected and analyzed. Phosphating is an important process in the pretreatment process of coating surface in mechanical processing plants. A large number of phosphorus-containing agents are needed in the 399 phosphating process, and the phosphate content of phosphating wastewater often exceeds the standard. The soluble orthophosphate forms in phosphating wastewater account for about $87.8 \%$ of total soluble phosphorus, which is comparable with the use of simulated phosphorus containing wastewater as experimental water. The photos 403 and water quality parameters of practical phosphate-containing wastewater before CR-LDH adsorption and after CR-LDH adsorption were given in Fig. S3 and Table 6, respectively.

Table 6 Water quality parameters of practical phosphate-containing wastewater before and after CR-LDH adsorption $\left(\mathrm{mg} \cdot \mathrm{L}^{-1}\right.$, except for $\left.\mathrm{pH}\right)$.

\begin{tabular}{cccccc}
\hline Process & $\mathrm{pH}$ & $\mathrm{COD}_{\mathrm{cr}}$ & $\begin{array}{c}\text { Turbidity } \\
\text { (NTU) }\end{array}$ & $\mathrm{NH}_{4}{ }^{-}-\mathrm{N}$ & $\mathrm{PO}_{4}{ }^{3-}-\mathrm{P}$ \\
\hline Before CR-LDH & 7.32 & 92.0 & 30.7 & 62 & 9.8 \\
adsorption & & & & & \\
After CR-LDH & & & & & \\
adsorption & 7.89 & 53 & 7 & 49.16 & 0.48 \\
\hline
\end{tabular}


First-class standard of
national discharge
6-9
60
1
5
0.5
standards

408

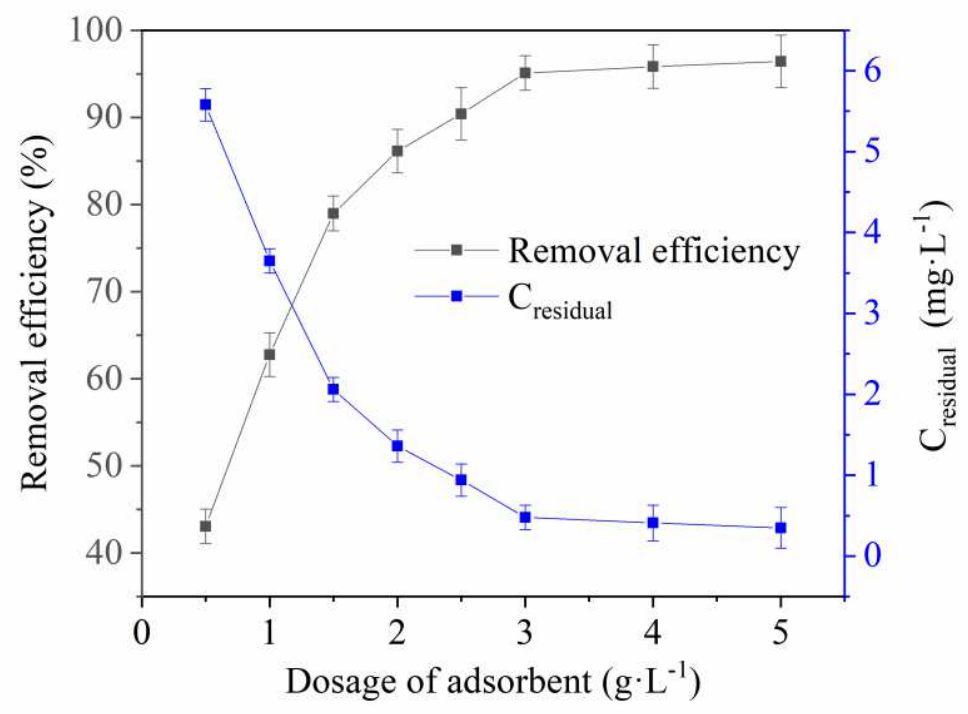

Fig. 7 Effect of dosages on the removal of phosphate from practical phosphate-containing wastewater.

In the applicability of CR-LDH test, $0.5,1,1.5,2,3,4$ and $5 \mathrm{~g} / \mathrm{L}$ of CR-LDH were added into the $100 \mathrm{~mL}$ practical phosphate-containing wastewater for the adsorption experiments, respectively. After adsorption for $8 \mathrm{~h}$ at $25^{\circ} \mathrm{C}$, the samples were filtered through $0.45 \mu \mathrm{m}$ cellulose filtered membrane and then diluted for further phosphate analysis. As exhibited in Fig. 7 and Table 5, the residual phosphate of practical wastewater was decreased gradually as the increase of CR-LDH dosage, while the phosphate removal rate was increased first and then stabilized. When the dosage of CR-LDH was $3 \mathrm{~g} / \mathrm{L}$, the residual phosphate concentration was $0.48 \mathrm{mg} \cdot \mathrm{L}^{-1}$ and the corresponding removal rate was $95.1 \%$, which met the first class discharge 
standard $\left(\leq 0.5 \mathrm{mg} \cdot \mathrm{L}^{-1}\right)$ in the integrated wastewater discharge standard (GB8978-1996). The effluent $\mathrm{pH}$ met the discharge standard and the COD, turbidity and $\mathrm{NH}_{4}{ }^{+}-\mathrm{N}$ were reduced by $42.39 \%, 77.20 \%$ and $20.71 \%$, respectively. The above results indicated that $\mathrm{CR}-\mathrm{LDH}$ had great potential for adsorbing phosphate from practical phosphate-containing wastewater.

\subsection{Adsorption mechanism}

In order to clarify the adsorption mechanism, FT-IR was used to find out the functional groups' changes of CR-LDH before and after adsorption of phosphate. As shown in Fig. S4, the peak at $3415.75 \mathrm{~cm}^{-1}$ and $1637.79 \mathrm{~cm}^{-1}$ were assigned to the stretching and bending vibration of the $-\mathrm{OH}$ in the CR-LDH and interstitial water molecules, respectively. After adsorbed phosphate, the peaks at $1003.28 \mathrm{~cm}^{-1}$ and 548 $\mathrm{cm}^{-1}$ appeared which were attributed to the stretching and bending vibration of phosphate. The band at $874 \mathrm{~cm}^{-1}$ belonged to the vibration of $\mathrm{P}-\mathrm{O}$ in $\mathrm{HPO}_{4}{ }^{2-}$, indicating that effective adsorption of phosphate by CR-LDH was existed.

The XRD spectra of CR-LDH after adsorption of phosphate is shown in Fig. 8. Compared to XRD pattern of CR-LDH before adsorption of phosphate, the diffraction peak intensity of boehmite was decreased and the characteristic diffraction peak of brucite was disappeared. New diffraction peaks of $\mathrm{Ca}_{2} \mathrm{P}_{2} \mathrm{O}_{7}, \mathrm{Ca}_{2} \mathrm{P}_{2}, \mathrm{Mg}_{3}\left(\mathrm{PO}_{4}\right)_{2}$ were appeared which might be due to that phosphate entered into the layered structure of CR-LDH after the adsorption process and $\mathrm{Ca}^{2+}$ dissolved on the surface combined with $\mathrm{HPO}_{4}{ }^{2-}$ hydrolyzed to form $\mathrm{CaHPO}_{4}$. After that, $\mathrm{CaHPO}_{4}$ was polymerized and dehydrated to form $\mathrm{Ca}_{2} \mathrm{P}_{2} \mathrm{O}_{7}$ precipitation. The peaks at $2 \theta$ of $26.47^{0}$ and $39.49^{0}$ were 
attributed to $\mathrm{CaO}$. The adsorption peak of $\mathrm{CaCO}_{3}$ was appeared at $2 \theta$ of $43.14^{0}$. The appearance of peaks at $2 \theta$ of $33.24^{0}, 35.73^{\circ}$ and $54.21^{0}$ identified the existence of $\mathrm{Fe}_{2} \mathrm{O}_{3}$. The reason for the existence of the above metal oxides in the XRD pattern of CR-LDH after adsorption of phosphate was due to that the raw material of carbide slag was industrial waste and the metal oxide didn't fully react during the preparation process of CR-LDH.

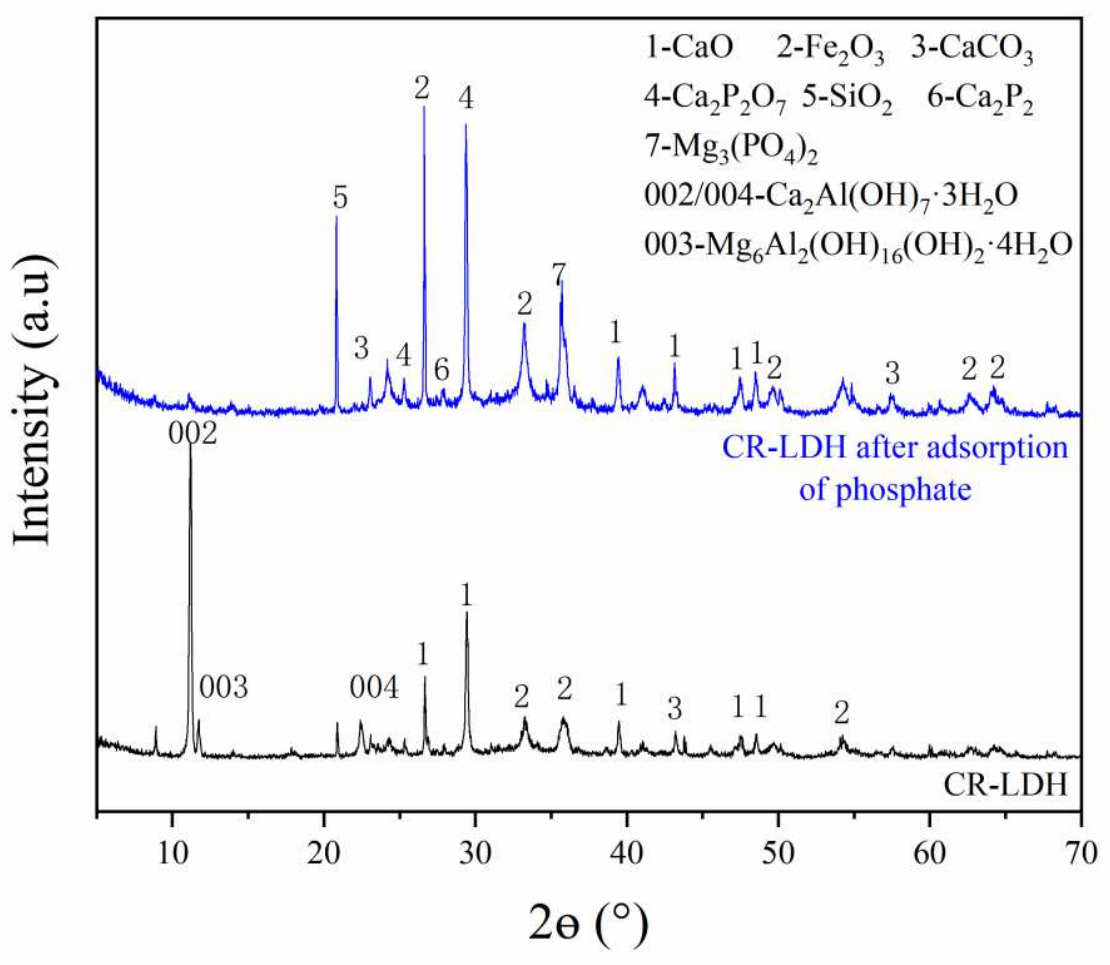

Fig. 8 XRD pattern of CR-LDH and after adsorption of phosphate.

According to the EDS results (Fig. 9a and Table 1), non-metallic P element was appeared in CR-LDH after adsorption of phosphate, indicating that the surface of the CR-LDH composite could adsorb phosphate by surface adsorption, surface complexation, electrostatic attraction and chemical precipitation. The SEM images of CR-LDH after adsorption of phosphate (Fig. 9b and Fig. 9c) exhibited a relatively flat, 
455

456

457

458

459

irregular block morphology and the surface gap of CR-LDH was filled, leading to the increase in the specific surface area which was conductive for the adsorption process.

During the adsorption process, the free metal cations might be combined with $\mathrm{PO}_{4}{ }^{3-}$ and hydroxyl groups to form phosphate or other metal oxides and then deposited on the surface of the adsorbent. $\Theta$
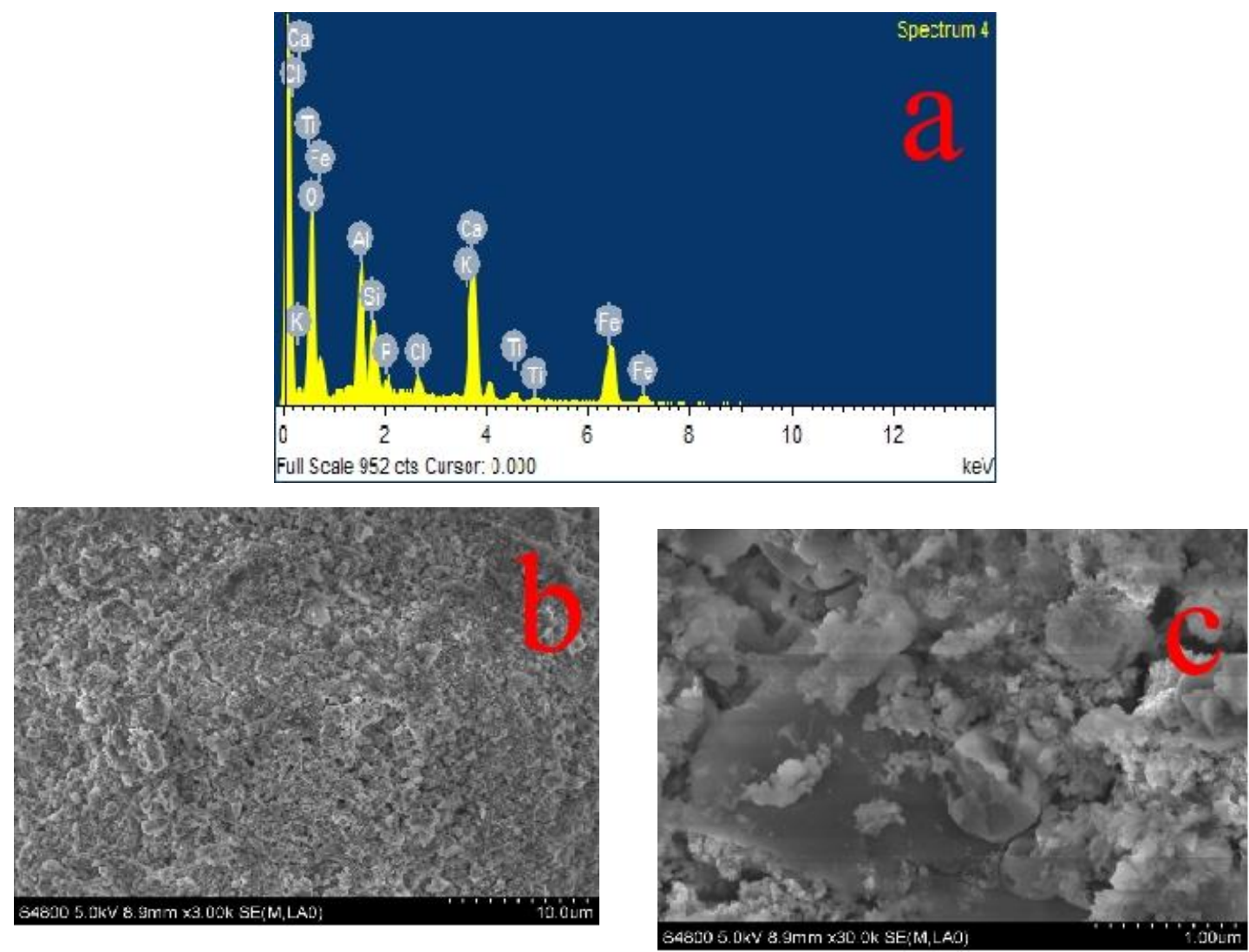

Fig. 9 EDS of CR-LDH after adsorption of phosphate (a) and SEM of CR-LDH after adsorption of phosphate (b and c). could infer that the adsorption of phosphate by CR-LDH might be through the 464 following four interactions: (1) physical adsorption; The strength of physical 465 adsorption mainly depends on the specific surface area and pore size distribution of adsorbent. Generally, the larger the specific surface area of adsorbent, the higher the 
adsorption capacity of physical adsorption. CR-LDH with surface area of $42.46 \mathrm{~m}^{2} \cdot \mathrm{g}^{-1}$ had a lamellar structure due to the large number of gaps on the surface and the relatively rough surface (Fig. 2), providing a great quantity of active adsorption sites for the adsorption of phosphate. Thus, part of phosphate could be adsorbed on the surface of CR-LDH by van der Waals force of physical adsorption. (2) ion exchange; The exchangeability of interlayer anions is one of the important properties of LDHs.

Some anions in the aqueous solution will enter the material ion layer, while the anions originally in the ion layer will transfer to the aqueous solution. The interlayer anions in the layered structure of CR-LDH in solution might be replaced by anions with stronger exchange performance to achieve partial adsorption of phosphate. (3) anion intercalation; Since CR-LDH laminates are positively charged, the anions in the solution will enter the layers of CR-LDH to balance the structure and electrical properties of the laminates, so anion intercalation plays an important role in the process of phosphate removed by CR-LDH. This inference was consistent with XRD results that the intensity of the hydrocalumite diffraction peak was decreased after the adsorption of phosphate, the characteristic diffraction peak of magnesia was disappeared, and the diffraction peak of $\mathrm{Ca}_{2} \mathrm{P}_{2} \mathrm{O}_{7}$ was appears, indicating that part of phosphate entered into the interlayer structure of CR-LDH. The phosphate on the surface of CR-LDH would form phosphorus-containing precipitate with dissolved $\mathrm{Mg}^{2+}$ and $\mathrm{Ca}^{2+}$. (4) chemical precipitation. The free metal cations $\left(\mathrm{Ca}^{2+}, \mathrm{Al}^{3+}, \mathrm{Fe}^{3+}\right.$, etc $)$ produced by CR-LDH would be combined with phosphate to form various precipitates and then deposited on the surface of adsorbent, leading to the flat surface 
489

490

491

492

493

494

495

496

497

498

499

500

501

502

503

504

505

506

507

508

509

510

of CR-LDH after adsorption of phosphate (Fig. 9b). The appearance of $\mathrm{Ca}_{2} \mathrm{P}_{2} \mathrm{O}_{7}$ in the

XRD pattern of CR-LDH after adsorption of phosphate suggested that $\mathrm{Ca}^{2+}$ dissolved from CR-LDH was combined with $\mathrm{HPO}_{4}{ }^{2-}$ to form $\mathrm{CaHPO}_{4}$ and then polymerize, dehydrated to obtain $\mathrm{Ca}_{2} \mathrm{P}_{2} \mathrm{O}_{7}$ precipitate (Fig. 8). The detection of $\mathrm{P}$ element in the EDS of CR-LDH after adsorption of phosphate also indicated that chemical prchemical precipitation was occurred in the process of phosphate adsorbed by CR-LDH (Fig. 9a).

\section{Conclusion}

In this study, adsorbent of CR-LDH were successfully designed via a simple method by using calcium carbide slag and red mud as raw materials. Characterization results showed that the synthesized CR-LDH had typical properties of LDH. The experimental data of phosphate adsorbed by CR-LDH could be well fitted by pseudosecond-order model and Langmuir isotherm model with theoretical maximum adsorption capacity of $16.06 \mathrm{mg} \cdot \mathrm{g}^{-1}$ at $25^{\circ} \mathrm{C}$, suggesting that it's a chemical and monolayer adsorption process. Based on the adsorption experimental results and characterization analysis, the adsorption of phosphate by CR-LDH was assumed to be through physical adsorption, ion exchange, anion intercalation and chemical precipitation. In brief, the CR-LDH prepared from calcium carbide slag and red mud was a effective adsorbent for treating practical phosphate-containing wastewater, which is helpful for the reuse of industrial waste resources, the reduction of environmental pollutants of phosphate and the protection of the environment.

\section{Ethics approval and consent to participate}


Not applicable.

\section{Consent for publication}

513 Not applicable.

\section{Authors Contributions}

Liping Xiao: Resources, Methodology, Investigation, Supervision, Conceptualization,

Project administration, Writing - review \& editing. Yan Li: Methodology,

517 Investigation, Resources, Writing - review \& editing. Qiaoping Kong: Writing -

518 original draft, Writing - review \& editing, Methodology, Investigation, Resources.

519 Yunlong Lan: review \& editing.

520 Availability of data and materials

521 Not applicable.

\section{Competing Interest}

523 The authors declare that they have no known competing financial interests or personal 524 relationships that could have appeared to influence the work reported in this paper.

\section{Acknowledgments}

526 This work was supported by the National Natural Science Foundation of China (NO.

52751474122 and NO. 51174267) and the Key projects of scientific research fund of

528 Liaoning Provincial Department of Education (NO. ZL002)

\section{References:}

531 Bacelo, H., Pintor, A.M.A., Santos, S.C.R., Boaventura, R.A.R., Botelho, C.M.S., 2020.

Performance and prospects of different adsorbents for phosphorus uptake and recovery 
533

534

535

536

537

538

539

540

541

542

543

544

545

546

547

548

549

550

551

552

553

554

from water. CHEMICAL ENGINEERING JOURNAL, 381, 122566.

Cao, H., Wu, X., Syed-Hassan, S.S.A., Zhang, S., Mood, S.H., Milan, Y.J.,

Garcia-Perez, M., 2020. Characteristics and mechanisms of phosphorous adsorption by rape straw-derived biochar functionalized with calcium from eggshell. BIORESOURCE TECHNOLOGY, 318.

Cheng, S., Shao, L., Ma, J., Xia, X., Liu, Y., Yang, Z., Yang, C., Li, S., 2019. Simultaneous removal of phosphates and dyes by Al-doped iron oxide decorated $\mathrm{MgAl}$ layered double hydroxide nanoflakes. ENVIRONMENTAL SCIENCE. NANO, 6, 2615-2625.

Cheng, X., Huang, X., Wang, X., Sun, D., 2010. Influence of calcination on the adsorptive removal of phosphate by $\mathrm{Zn}$-Al layered double hydroxides from excess sludge liquor. JOURNAL OF HAZARDOUS MATERIALS, 177, 516-523.

Cheng, X., Huang, X., Wang, X., Zhao, B., Chen, A., Sun, D., 2009. Phosphate adsorption from sewage sludge filtrate using zinc-aluminum layered double hydroxides. JOURNAL OF HAZARDOUS MATERIALS, 169, 958-964.

Chitrakar, R., Tezuka, S., Sonoda, A., Sakane, K., Ooi, K., Hirotsu, T., 2005. Adsorption of phosphate from seawater on calcined MgMn-layered double hydroxides. JOURNAL OF COLLOID AND INTERFACE SCIENCE, 290, 45-51.

Dox, K., Pareijn, R., Everaert, M., Smolders, E., 2019. Phosphorus recycling from urine using layered double hydroxides: A kinetic study. APPLIED CLAY SCIENCE, $182,105255$.

Guo, Z., Li, J., Guo, Z., Guo, Q., Zhu, B., 2017. Phosphorus removal from aqueous 
555

556

557

558

559

560

561

562

563

564

565

566

567

568

569

570

571

572

573 efficient removal of heavy metals from aqueous solutions. INTERNATIONAL

574

575

576

solution in parent and aluminum-modified eggshells: thermodynamics and kinetics, adsorption mechanism, and diffusion process. ENVIRONMENTAL SCIENCE AND POLLUTION RESEARCH, 24, 14525-14536.

Hu, P., Zhang, Y., Lv, F., Tong, W., Xin, H., Meng, Z., Wang, X., Chu, P.K., 2017. Preparation of layered double hydroxides using boron mud and red mud industrial wastes and adsorption mechanism to phosphate. WATER AND ENVIRONMENT JOURNAL : WEJ, 31, 145-157.

Jia, Z., Hao, S., Lu, X., 2018. Exfoliated Mg-Al-Fe layered double hydroxides/polyether sulfone mixed matrix membranes for adsorption of phosphate and fluoride from aqueous solutions. JOURNAL OF ENVIRONMENTAL SCIENCES, 70, 63-73.

Jiang, Y., Chen, Y., Du, Q., Shi, J., 2019. Adsorption of different forms of phosphorus on modified corn bracts. WATER ENVIRONMENT RESEARCH, 91, 748-755.

Jiang, Y., Li, A., Deng, H., Ye, C., Li, Y., 2019. Phosphate adsorption from wastewater using ZnAl-LDO-loaded modified banana straw biochar. ENVIRONMENTAL SCIENCE AND POLLUTION RESEARCH, 26, 18343-18353.

Kong, Q., Preis, S., Li, L., Luo, P., Hu, Y., Wei, C., 2020. Graphene oxide-terminated hyperbranched amino polymer-carboxymethyl cellulose ternary nanocomposite for JOURNAL OF BIOLOGICAL MACROMOLECULES, 149, 581-592.

Kong, Q., Shi, X., Ma, W., Zhang, F., Yu, T., Zhao, F., Zhao, D., Wei, C., 2021. Strategies to improve the adsorption properties of graphene-based adsorbent towards 
577

578

579

580

581

582

583

584

585

586

587

588

589

590

591

592

593

594

595

596

597

598

heavy metal ions and their compound pollutants: A review. JOURNAL OF HAZARDOUS MATERIALS, 415, 125690-125690.

Kong, Q., Wei, J., Hu, Y., Wei, C., 2019. Fabrication of terminal amino hyperbranched polymer modified graphene oxide and its prominent adsorption performance towards Cr(VI). JOURNAL OF HAZARDOUS MATERIALS, 363, 161-169.

Kuzawa, K., Jung, Y., Kiso, Y., Yamada, T., Nagai, M., Lee, T., 2006. Phosphate removal and recovery with a synthetic hydrotalcite as an adsorbent. CHEMOSPHERE, $62,45-52$.

Li, X., Xie, Q., Kuang, Y., Wu, D., 2021. Coupled influence of pH and dissolved organic carbon on the immobilization of phosphorus by lanthanum-modified zeolite. CHEMOSPHERE, 274.

Liu, C., Zhang, M., Pan, G., Lundehoj, L., Nielsen, U.G., Shi, Y., Hansen, H.C.B., 2019. Phosphate capture by ultrathin MgAl layered double hydroxide nanoparticles. APPLIED CLAY SCIENCE, 177, 82-90.

Razmi, B., Ghasemi-Fasaei, R., 2018. Investigation of Taguchi optimization, equilibrium isotherms, and kinetic modeling for phosphorus adsorption onto natural zeolite of clinoptilolite type. ADSORPTION SCIENCE \& TECHNOLOGY, 36, 1470-1483.

Samaraweera, H., Sharp, A., Edwards, J., Jr. Pittman, C.U., Zhang, X., Hassan, E.B., Thirumalai, R.V.K.G., Warren, S., Reid, C., Mlsna, T., 2021. Lignite, thermally-modified and $\mathrm{Ca} / \mathrm{Mg}$-modified lignite for phosphate remediation. SCIENCE OF THE TOTAL ENVIRONMENT, 773. 
599

600

601

602

603

604

605

606

607

608

609

610

611

612

613

614

615

616

617

618

619

620

Seftel, E.M., Ciocarlan, R.G., Michielsen, B., Meynen, V., Mullens, S., Cool, P., 2018. Insights into phosphate adsorption behavior on structurally modified ZnAl layered double hydroxides. APPLIED CLAY SCIENCE, 165, 234-246.

Tie, J., Chen, D., Wan, Y., Yan, C., Zhang, X., 2013. Adsorption removal of phosphorus from aqueous solution by heat-activated alum sludge. ASIAN JOURNAL OF CHEMISTRY, 25, 9129-9134.

Wang, Z., Miao, R., Ning, P., He, L., Guan, Q., 2021. From wastes to functions: A paper mill sludge-based calcium-containing porous biochar adsorbent for phosphorus removal. JOURNAL OF COLLOID AND INTERFACE SCIENCE, 593, 434-446.

Yang, F., Zhang, S., Sun, Y., Tsang, D.C.W., Cheng, K., Ok, Y.S., 2019. Assembling biochar with various layered double hydroxides for enhancement of phosphorus recovery. JOURNAL OF HAZARDOUS MATERIALS, 365, 665-673.

Yang, K., Yan, L., Yang, Y., Yu, S., Shan, R., Yu, H., Zhu, B., Du, B., 2014. Adsorptive removal of phosphate by $\mathrm{Mg}-\mathrm{Al}$ and $\mathrm{Zn}-\mathrm{Al}$ layered double hydroxides: Kinetics, isotherms and mechanisms. SEPARATION AND PURIFICATION TECHNOLOGY, 124, $36-42$.

Zhang, J., Xia, Q., Hong, X., Chen, J., Liu, D., 2021. Synthesis of layered double hydroxides with nitrate and its adsorption properties of phosphate. WATER SCIENCE AND TECHNOLOGY, 83, 100-110.

Zhang, Z., Yan, L., Yu, H., Yan, T., Li, X., 2019. Adsorption of phosphate from aqueous solution by vegetable biochar/layered double oxides: Fast removal and mechanistic studies. BIORESOURCE TECHNOLOGY, 284, 65-71. 
621 Zhu, D., Yang, H., Chen, X., Chen, W., Cai, N., Chen, Y., Zhang, S., Chen, H., 2021.

622 Temperature-dependent magnesium citrate modified formation of $\mathrm{MgO}$ nanoparticles

623 biochar composites with efficient phosphate removal. CHEMOSPHERE, 274.

624 


\section{Supplementary Files}

This is a list of supplementary files associated with this preprint. Click to download.

- SupplementaryMaterial.docx 